\title{
KNOWLEDGE-BASED GENERATION OF OPERATIONAL PROCEDURES FOR CONSTRUCTION OF WOOD STRUCTURES
}

\author{
Nakajima Masao \\ Department of Architecture, College of Engineering, \\ Kanto Gakuin University, JAPAN \\ mnaka@kanto-gakuin.ac.jp
}

\begin{abstract}
This paper focuses on non-numerical information such as operational procedures for processing and assembling members used in wooden construction systems and aims at developing a knowledge-based system (KBS) for generation and control of this information. The process involves dividing the building construction system into basic units, defining and describing those units, and then inputting this information into a computer-based KBS. The system then produces a detailed output of the processing and assembly steps for each of wooden members in the structure using knowledge about operations and construction methods. This system was applied to various model structures, and activity procedures generated are demonstrated to be accurate.
\end{abstract}

Keywords: knowledge-based system, generation system of activity, operational procedures, building construction system, wood structure, Prolog

\section{INTRODUCTION}

In general, when designing and developing a new construction method properly, besides evaluation from a functional aspect concerned with habitability, safety, and other matters, evaluation from a production aspect is indispensable. However, evaluating a construction method from a production aspect currently falls remarkably behind the evaluation from functional aspects, and therefore development of a technique to evaluate the productive characteristics of a construction method in detail is a current subject for research.

The purpose of this study is therefore following each item focussing on the operational procedures.

(A) To generalize the relation of various characteristics for a construction method of a wooden house with the content of and sequence of operations, and to establish a technique to predict such elements of production characteristics from the characteristics of a construction system.

(B) To evaluate a change in production characteristics of a construction method accompanied with a change in joint method between members, connection relations and so forth based on the results obtained above and to establish a method to obtain fundamental data for designing, improving and developing a new construction system.

In this report, an estimation method of the operational procedures was developed using Knowledge Engineering. The target of this study is set to be exclusively detached type wooden houses with up to two stories high which are built by a post-and-beam, light-framed platform, industrialized wooden panel and their improved construction methods, which are currently the main construction methods in Japan. In addition, this study is focussing on the operational procedures in carpentry work, which constitutes an essential part of each construction method above and also occupies a dominant position in a total stage of construction tasks.

\section{FRAMEWORK FOR GENERATING THE OPERATIONAL PROCEDURES}

\subsection{Relation between operational procedures and construction method}

The primary purpose to execute various kinds of operation at an actual building site is to change the state of individual members, as well as, of connection and joint between them, which are essential elements of some construction method. In addition to changes in characteristics of a construction method such as changes in type, shape and dimension of elements, or changes in shape, method, fastening material of joint parts, changes in a construction method usually cause significant changes in necessity of adjustment at a building site which will occur from results of changes in required processing accuracy, assembling accuracy, assembling sequence with other member to be connected and handling accuracy. In this study, the relation between a construction method and operations is recognized in such a way that changes in construction methods appears as changes in operational procedures as shown in Figure 1. Therefore in order to make evaluation of a construction method from an operational aspect possible, it is essential

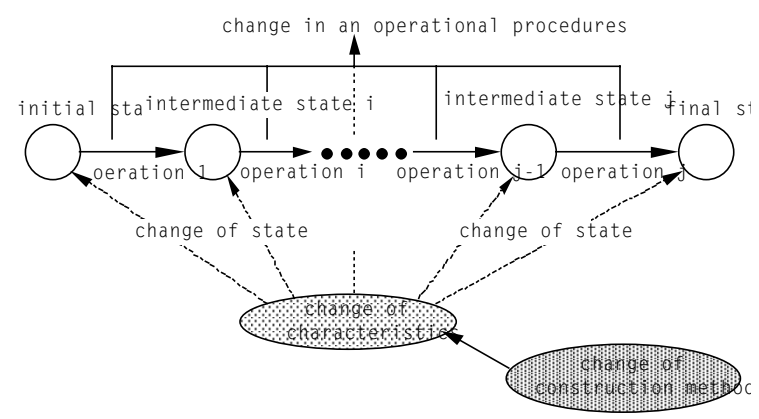

Figure 1. Relation between construction method and operational procedures. 
and indispensable to clarify the relation between the factors for such various characteristics of a construction method and operations.

In the meantime, generally speaking, when evaluating a construction method from an operational aspect, on what level of operation (detailed degree of operation) the evaluation should be carried out, will be an important issue. Because evaluation of a construction method will be the purpose of this study, it is required that a change in a shape of a member and joint part, namely a change in detail must be dealt with. Accordingly, as for an operation level to be generated, an element operation level, which is the minimum task unit directly reflecting a change in a construction method, was adopted.

\subsection{Classification of operations and characteristics of construction methods}

1) Survey on operations carried out at construction site

For the purpose of clarifying the relation and regularity of the factors on characteristics of a construction method with the operational procedures, time study on operation at a construction site in an element operation level has been carried out [1]. Surveyed objects were four houses built by a post-and-beam construction, two houses by a lightframed platform construction, and two houses by an industrialized wooden panel construction. Each of them was in standard in terms of a plan, elevation, specification, scale and method of work execution. Based on another survey results concerning to an improvement technique of a conventional post-and-beam construction [2], these three construction methods were selected as objects for analysis because it is considered that an improvement and development technique of a wooden house construction can be resulted, from these three principal construction methods.

In the case of site survey, the content, sequence and amount of operation were recorded respectively as well as measuring the working hours with the accuracy of a second unit on each worker and on each wooden member through applying a continuous time measuring method used in Industrial Engineering field. Based on these results, 169 members were abstracted from a conventional post-andbeam construction, 110 members from a light-framed platform construction, 86 members from an industrialized wooden panel construction, consequently 365 members in total, so that each item of characteristics of a construction method can be included. Subsequently the relation of characteristics of a construction method relating to each member, joint and so forth with the actual operational procedures was analyzed.

\section{2) Classification of observed operations}

Each operation observed at the construction site can be roughly divided into three types, namely "main operation", "ancillary operation" and "preparation operation", from a meaning and function each operation has. The main operation is a series of operations, which is executed by making a member as the direct object to change a shape and dimension of a member, and to join and bind a member. Operations such as "cutting", "machining", "drilling", "chipping", "grooving", "application of adhesives", "assembling", "nailing", "bolting" fall under it. On the other hand, the ancillary operations can be classified as the operations to set technical conditions for conducting main operations in order, and accordingly "measurement of dimension", "marking", "temporary assembling", "temporary fixing", "horizontal and vertical inspection" and others are included. The preparation operation can be classified as operations for setting the tools, materials, position and condition of a worker and so forth in order, to carry out the main and ancillary operations. Consequently "transportation of member", "lifting of member", "erecting", "preparation of appliances and tools", "movement of worker", "preparation of scaffold" and so on correspond to it.

3) Characteristics of a construction method to determine the operational procedures

Based on the analysis mentioned above and other existing research [3, 4], characteristics of a construction method especially in association with the operational procedures will be abstracted as follows.

As factors regarding a member, there are a type of material, dimension, shape, spatial position, cross section shape, directional property, accuracy (position, dimension, processing of a joint part, assembling) and so forth. In addition, as factors concerning the counter member to be jointed, a shape, joint method, relation of spatial position, each kind of accuracy including the joint accuracy and others will be pointed out.

\section{METHODOLOGY FOR GENERATING THE OPERATIONAL PROCEDURES}

\subsection{States of a member and the functions of operations}

The operation is carried out to change various states of a member in order to realize a state as designed (it is defined as a "final state") from a state just when a member has been transported into a building site (it is defined as an "initial state"). By analyzing the survey results, in terms of a state of such a member, it was found that there were following three types in a wooden house construction.

(A) Shape state

1) Section shape state: A state of cross section shape over the total length or more than half length of a member, of which purpose is not to be joined with other member.

2) Whole dimension state: A dimension state of the length, width and thickness as a whole member.

3) Shape state of a joint part: A shape state of each part in a joint part with other member.

(B) Joint state

1) Assembling state: Whether a member is assembled at a position as designed.

2) Fastening state: Whether a member is bound tightly with the counter member by metallic material, adhesives and so on.

(C) Position state

1) Horizontal and vertical position state of a member in a whole building: Spatial coordinates of a reference point set on a member.

2) State of directional property of a member: State of horizontal and vertical property of a member which is 


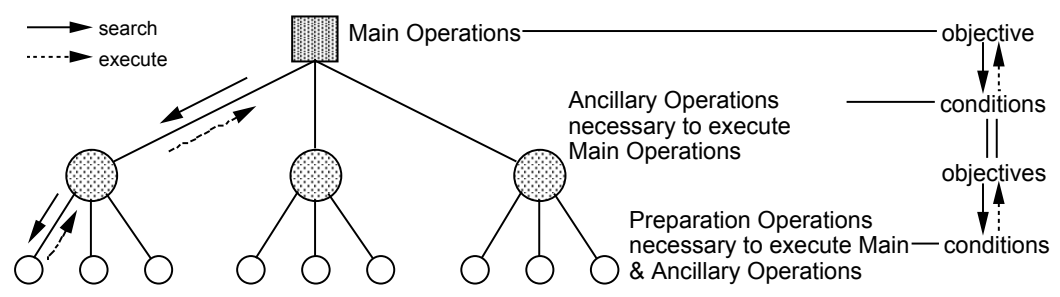

Figure 2. Hierarchical structure of operations to construct a building system.

defined separately

Based on this result, all operations performed at a building site can be dealt with as an action to change each state mentioned above directly or indirectly. That is, the function of each main operation can be basically defined as a direct change in each of a shape and joint state of a member (for example, a change in a state of length $\rightarrow$ cutting, a change in a state of a cross section shape $\rightarrow$ grooving, planing and so forth). On the other hand, the ancillary operation, to put a technical condition for executing the main operation in order, is concerned with an indirect change of each state as a prerequisite condition for executing the main operation (for example, a prerequisite condition of fastening $\rightarrow$ horizontal and vertical inspection and so on). In addition, out of the preparation operations, operation of transportation of a member, lifting, erecting and others can be defined as those to change directly a position state of a member. Furthermore the other preparation operation can be defined as those to arrange the tools, material, and work environmental condition necessary for carrying out main operations and ancillary operations.

\subsection{Hierarchical structure of operation and its sequence principle}

1) Hierarchical structure of operation and sequence principle

When the sequence of operation at a building site is observed in a level of the main operation, ancillary operation and preparation operation, its execution sequence forms always the hierarchical structure as shown in Figure 2. That is, first of all, the sequence of a change in a state of member is determined, and then the main operation corresponding to it will be carried out. On that occasion, a technical condition to be a premise on executing the main operation concerned will be searched, and furthermore it will be judged whether its work environmental condition should be put in order or not. As a result, by pursuing such a thought process conversely, the concrete operation will be carried out starting from the lowest hierarchy (preparation operation). A hierarchical flow of the search and execution in connection with one main operation as explained above, is the most fundamental principle on an operation sequence at a building site.

2) Sequence principle relating to "adjustment at a building site"

Accordingly, when generating a sequence of total operation executed for a certain specific member, it is the most fundamental to make clear sequence rules of the main operation. Out of such rules, "adjustment at a building site", which used to occur characteristically in the assembling operation at a building site, is especially important. "Adjustment at a building site" is an activity, which becomes necessary basically when the assembling accuracy of a member concerned is higher than that of a counter member to be jointed. Accordingly a sequence of processing and assembling operation will be restrained depending on whether it is required or not. Namely, in general, the processing operation should be conducted prior to the assembling operation. But when "adjustment at a building site" is required for the certain jointing operation, depending on whether the priority of assemble of counter member is higher or lower than that of member concerned, the sequence relation between assembling operation of a member concerned and processing operation of its joint part will be reversed.

On the other hand, as for the processing operation being unnecessary for "adjustment at a building site", whenever and wherever the processing operation can be carried out if it is done before the assembling operation (namely precutting is possible), and just a sequence rule between the processing operations acts.

\subsection{Generation principle of operations}

\section{1) Main operation}

Through the analysis of the content of operation and a state of member, the content of main operation was generated by a following method. As shown in Figure 3, an initial state and final state referring to a shape state and joint state of a member are compared, and subsequently if they are in accord with each other, the generation operation will be finished. If they are not in accord with each other, the necessary operation will be generated in regular order from one which is not contrary to a sequence rule of the main operation as stated in the next section. In this occasion, the relation of each main operation concerning processing, assembling and fastening with a change in a state of a member is defined as knowledge.

With regard to a cross section of member and a shape of joint part, they were decomposed into an element shape as shown in Figure 4. The element composition of the actual sections of each member and shape of joint part

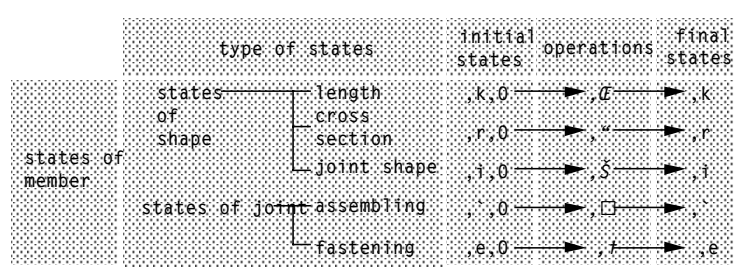

Figure 3. Generation principle for main operations. 

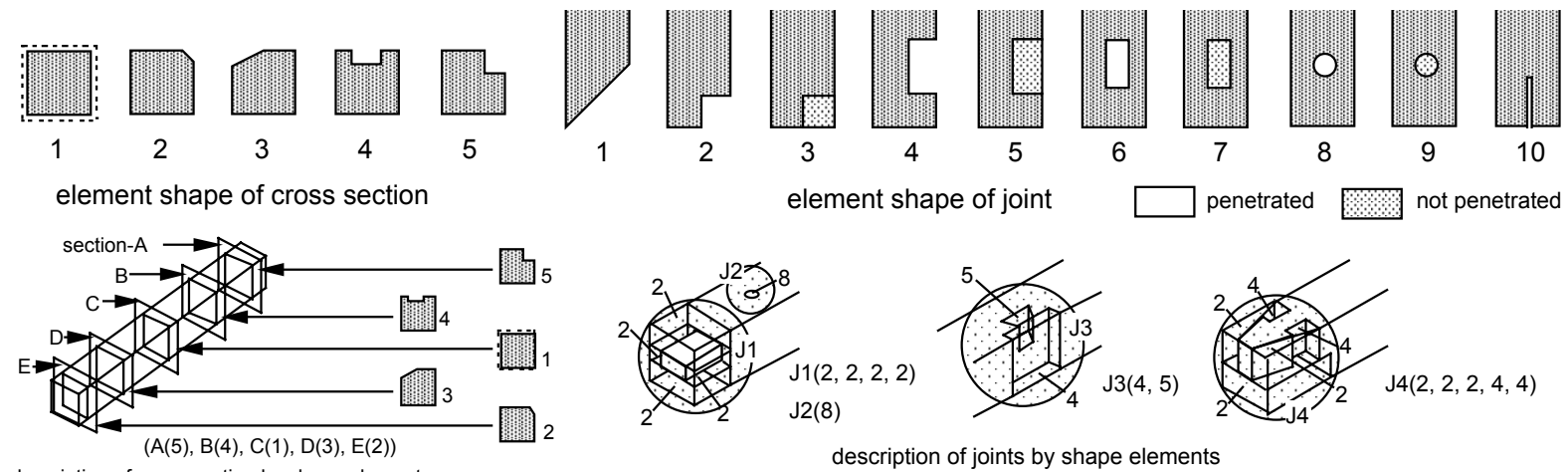

element shape of joint
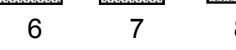

9

10

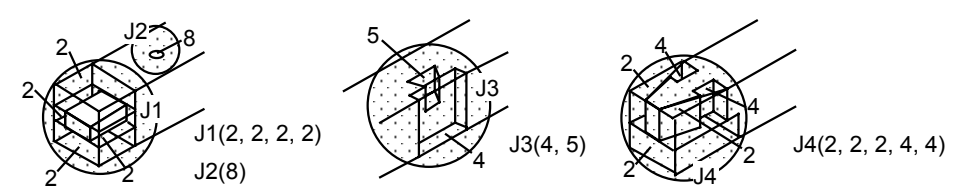

description of joints by shape elements

Figure 4. Shape elements and example descriptions of cross section and joints.

were given as knowledge, using description method shown in Figure 4, together with the operations necessary for processing each element shape. Operations necessary for processing a section or a joint part of member can be generated using this knowledge.

\section{2) Ancillary operation}

The ancillary operation, such as measurement of dimension, temporary assembling, temporary fixing, inspection of horizontal and vertical and so forth, can be generated from a function of main operation, member characteristics of a member concerned, joint characteristics with other member and so on. An example of vertical inspection is shown in Figure 5(a).

\section{3) Preparation operation}

As regards the preparation operation, parameters were provided for monitoring the material, tools, position and condition of workers. In the meantime, a condition for executing them was given as knowledge, and then through checking a sufficiency about an execution condition by referring the monitor, the required preparation operation was to be generated (Figure 5(b)). Furthermore, in this study, as well as the necessity of scaffold preparation depending on an assembling position of member, an approximate changing process in location of member at the site in response to characteristics of a construction method can be simulated.

\subsection{Generation principle of operations sequence}

With respect to a rule regarding an operation sequence, there is a rule as a principle as mentioned in previous section. Whereas the sequential relation among the main

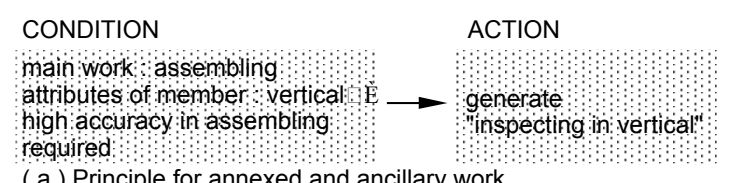

(a) Principle for annexed and ancillary work

prerequisites o execute nath procation of materals tool workers requír annexed/ancillary work :

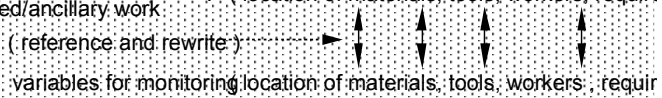

(b) Principle for preparation work

Figure 5. Generation principle for the ancillary operations and preparation operations. operation, ancillary operation and preparation operation is thought to be decided hierarchical structurally, further another sequence rule will act between main operations or between the preparation operations which change a position state. In this section, a formation method of a sequence will be explained focussing on these operations.

\section{1) Main operation}

Between the main operations, three kinds of a sequence rule were provided as shown in Table 1.

Rule- 1 is a rule with the lowest priority and is applied unless Rule- 2 and -3 fall within the purview of. Rule- 2 is a rule to judge the necessity of "adjustment at a building site" in every joint point. It is constructed based on the difference in each kind of accuracy between a member concerned and counter member to be connected, as well as the connection relation, relation of spatial position, or the joint relation. When it is judged here that "adjustment at a building site" is necessary, the next rule- 3 will be applied. Rule- 3 is a rule to decide the relation of processing a joint part with an assembling sequence, when "adjustment at a building site" is necessary.

\section{2) Transportation and lifting operation}

When processing, assembling and fastening operations to be executed in the next step are decided, based on the knowledge and rules relating to the place where each operation should be conducted, the transportation and lifting operations will be determined by generating them one by one using the information on the position of a member at present. In this case, it was assumed that

Table 1. Rules to determine the precedence of main operations.

\begin{tabular}{l}
\hline No. \\
\hline Rule-1. The priority is given in next order. \\
operations which change the length > operations which change the \\
joint shape > operations which change the cross section > operation \\
whch change the assembling state > operations which change the \\
fastening state
\end{tabular}


processing operations unnecessary for the adjustment at a building site should be executed in a construction shed or a processing places which is set up in a building lot. Processing operations necessary for the adjustment at a building site should be done at a processing place near an assembling place of the member, and in addition, assembling and fastening operations should be done at an assembling place of that member.

\subsection{Description formula of data to generate the operational procedures}

In connection with the data for characteristics of a construction method, a description formula shown below was employed using a list structure to put the data into this system.

data (n, L1, L2, L3, L4, L5, L6, L7, L8, L9, L10)

where:

n: data number

L1: list of characteristic data of member concerned

L2: list of characteristic data of counter members

L3: list of positional data necessary to cut members

L4: list of specific data necessary to process the joints of members

L5: list of data to describe the initial and final length state of members

L6: list of data to describe the initial and final joint shape state members before assembling

L7: list of data to describe the initial and final joints shape state of members after assembling

L8: list of data to describe the initial and final cross section state of members

L9: list of data to describe the initial and final fastening state of members before assembling

L10: list of data to describe the initial and final fastening state of members after assembling

\subsection{Structure of the generation system}

Based on a principle explained above, a generation system was developed as a "production system". A structure and a data process flow of this system is shown in Figure 6. A knowledge base composed of fact sentences and rule sentences about a construction method and operations was constructed, and concurrently an inference mechanism based on each principle stated above was built in as an inference engine. Furthermore, a state of tools, members and workers at a certain time point is temporarily stored in the working memory, and rewriting is carried out every time whenever each state has been changed after executing some operation. When a state of a member is unified with a final state, completion of operation is regarded to be realized, and simultaneously writing out of the operations generated in the meantime is to be done in regular order of execution. As a tool for constructing a generation system, Prolog, which comes into wide use as the artificial intelligence programming language, was employed. This program is composed of 189 kinds of rule sentence and 124 kinds of fact sentence in total.

\section{VERIFICATION OF SYSTEM PERFORMANCE}

\subsection{Adaptability to detailed change of construction method}

To verify the adaptability of this system to the change of detailed construction method, a model shown in Figure 7(a) was employed as the object. The generation results regarding a sill-1 are shown in Figure 7(b). A conventional case in which processing and assembling are carried out at a construction site is shown in a left column, and in a right column, a case in which a precut lumber is used is shown. The generation results for a conventional method were compared with the survey results done at a building site mentioned earlier. Consequently it could be confirmed that all operations of processing for the adjustment at a building site with an anchor bolt, transportation of a member and so forth were properly generated. In case of using a member which length and joint part connected with a sill-2 are precut, the operation was not generated just at such precut parts, and necessary operations were generated at the other part in the same manner as that in a conventional member made of normal lumber. So it is verified that this system can be adaptable to detailed change of construction method.

4.2 Generation of additional possible solutions using the backtrack function of Prolog

In this technique, conforming to a sequence rules, all of a

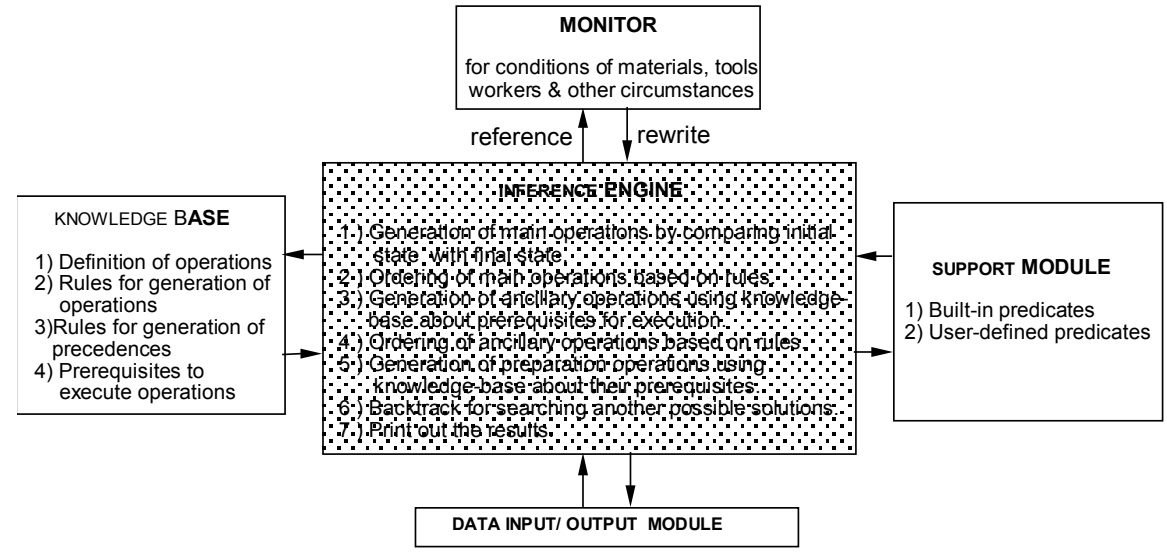

Figure 6. Structure of KBS for generation of operational procedures. 


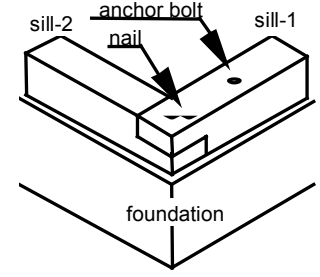

(a) Sill and foundation model

\begin{tabular}{|c|c|c|}
\hline $\begin{array}{l}\text { Result of normal lumber } \\
\text { processed in field }\end{array}$ & Remarks & Result of precut lumber \\
\hline sagvousva idou(buzaiokiba) & Move to stock vard & sagyousva idou(buzaiokiba) \\
\hline buzai unvan (kakoubasvo) & Carrv materials to & \\
\hline Isunpou vougu . & Prepare tools for measuring and & \\
\hline \{sunnou\} & Measure length & \\
\hline [sumituke vougu] & Prepare tools for & \\
\hline$\{$ sumi $(\mathrm{n})\}$ & Mark the cutting postion & \\
\hline [nokol & Prepare hand & \\
\hline $\mathrm{n}$ noko & Cut the length by hand saw & at the factory \\
\hline Isunpou yougu & Prepare measuring tools & \\
\hline$\{$ sunpou\} & Measure length & \\
\hline [sumituke vougu] & Prepare tools for & \\
\hline \{sumi (s)? & Mark the shane of ioints & \\
\hline [nokol & Prepare hand & \\
\hline s2 noko nok & Cut the ioint by saw & - \\
\hline buzai unpan (settibasvo) & Carrv member to assembly place $\square(a$ & buzai unpan (settibasvo) \\
\hline \{genba\} & Adiust at the site & $\{g e n b a\}$ \\
\hline [sumituke vougu] & Prepare tools for & [sumituke vougu] \\
\hline$\{\underline{\text { sumi }}(\mathrm{s})\}$ & Mark the bolt position & $\{\underline{g}$ sumi $(\mathrm{s})\}$ \\
\hline [drill] & Prepare drill & [drill] \\
\hline $\mathrm{g}(\mathrm{s} 7$ drill) & Drill holes for bolts & $\mathrm{g}(\mathrm{s} 7$ drill) \\
\hline kumitate & Assemble members & kumitate \\
\hline [kanazuti $\rceil$ & Prepare hammer & [kanazuti \\
\hline kugi (dodai2) & Nail to Sill 2 & kugi (dodai 2) \\
\hline [bolt1 & Prepare tools for fastening & [bolt $\rceil$ \\
\hline$\underline{\text { bolt (kiso) }}$ & Fasten bolts & bolt (kiso) \\
\hline $\begin{array}{l}\text { Legend No mark: main on } \\
\text { f }: \text { : ancillary ope }\end{array}$ & $\begin{array}{l}\text { buzai unpan }() \text { carrv me } \\
\mathrm{g}() \text { operations to be adi }\end{array}$ & $\begin{array}{l}\text { mbers (destination) } \\
\text { usted in field (kinds of operation) }\end{array}$ \\
\hline
\end{tabular}

Figure 7. Model and its generated results of processing assembling procedures to construct a sill by normal and by precut lumber.

possible operation sequence are searched by utilizing the backtrack function of Prolog. To confirm this function, as shown in Figure 8(a), rather complicated joint called "Okkake-daisen" which is often used to connect two horizontal structural members on the straight in traditional Japanese wooden houses were employed as a model. One of generated results and other possible operational procedures obtained by backtrack are shown in Figure 8(b). As there are many parts to process to form a final shape of this joint, there are many solutions to reach the goal as shown in Figure 8(c) which is drawn based on the results above. Though this model is rather simple, the system generates more than one thousand possible solutions, so in more complicated case such as total structure model which contains more than 100 elements and 1000 joints, this system may produce tremendous number of possible solutions. Consequently, some optimization technique should be considered in order to narrow the field of results to one or a few that most closely meets the needs of the user.

\section{CONCLUSIONS}

In this report, in order to make the evaluation of a construction method for a wooden house from a production aspect possible, a knowledge-based system to generate the operational procedures necessary for processing and assembling an individual member was constructed and its effectiveness was confirmed by two examples of trial. For
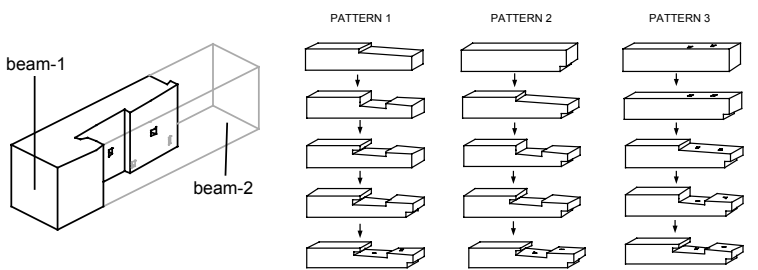

(a) "Okkake-daisen" model.

(c) Some Possible processing step nottarn generated by this system.

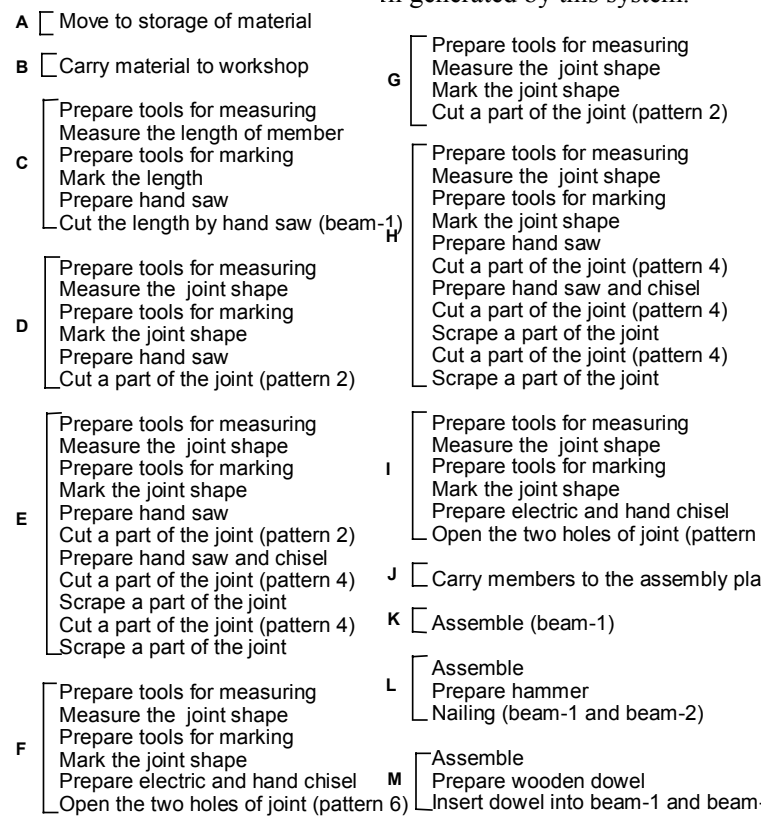

(b) One of generated result for construction of "Okkake-daisen".

Figure 8. "Okkake-daisen" model and its possible processing procedures generated by backtrack function of Prolog.

the future, in concert with the development of an evaluation method for the almost innumerable applicable operation sequences generated by a backtrack function of Prolog, the development of an automatic generation technique of input data in linkage with CAD system will be a main subject toward practical use.

\section{REFERENCES}

[1] Nakajima, M., Kouhiro K., "Study on the Analysis and Evaluation Method of Production Characteristics for the Wooden Houses", Journal of Structural and Construction Engineering, No.351, pp.1-11, 1985.

[2] Nakajima, M., Kouhiro K.. "Survey and Analysis on the Newly Developed Wooden Construction", Kenchiku Chishiki, Vol.23, No.275, pp60-63, 1981.

[3] Konishi,T., Chatani,M., Aoki,Y., "Studies on Graphic Application of the Building System by Symbolized Building Joints Part 1", Transactions of the Architectural Institute of Japan, No.297, pp71-77. 1980.

[4] Kamimura,K., Konishi,T., Kittaka, S., \& Shiroma, I. "Study on Description of Building System", Proceedings of Annual Meeting of Architectural Institute of Japan, Tokyo, pp625-626, 1987. 